\title{
La Hipnosis en Obstetricia
}

\author{
Primeras observaciones de su empleo en la ciudad de Bucaramanga \\ PRIMERAS OBSERVACIONES DE SU EMPLEO \\ EN LA CIUDAD DE BUCARAMANGA
}

Comunicación Prelininar

Dr. Isaías Arenas Buenahora, Miembro del Equipo "Iván P. Pávlov" de Bucaramanga

\section{INTRODUCCION}

En muy diversos campos de la medicina la hipnosis ha demostrado ser una medida terapéutica de valor extraordinario, ya sea empleada como terapia exclusiva o como factor coadyuvante en el plan general de tratamiento.

Es la Obstetricia una de las ramas en las que la hipnosis encuentra un vasto campo de acción y en la que, aplicada con buen criterio y con técnica adecuada, los efectos benéficos se manifiestan en forma más objetiva y precoz.

Desde hace seis meses comenzamos a emplearla en nuestra clientela privada, principalmente en casos de hiperemesis gravídica. Más tarde, la hemos aplicado en unos pocos casos de parto espontáneo, parto intervenido con fórceps y episiotomía.

Nos ha movido a presentar nuestra modesta experiencia, el interés de crear una mayor inquietud en nuestro medio por la aplicación de los métodos hipno-sugestivos que prestan tanto beneficio no solo para el médico sino también para el paciente.

Reconocemos que nuestra casuística no nos permite establecer aún conclusiones definitivas. Pero abrigamos la esperanza de que ella pueda servir de base a futuros trabajos más completos.

\footnotetext{
* Comunicación presentada al III Simposio Colombiano de Sicoprofilaxis Obstétrica - Julio de 1961 — Bucaramanga, Colombia.
} 


\section{MATERIAL Y METODOS}

La presente comunicación comprende el estudio de 24 casos. De éstos, 20 corresponden a pacientes con hiperemesis gravídica, 2 a casos de parto espontáneo y 2 a casos de parto intervenido con fórceps y episiotomía.

En las 20 pacientes del primer grupo el vómito fué el signo constante, con una frecuencia mínima de 3 veces por día y máxima de 10. Todas habian estado sometidas a diversos tratamientos medicamentosos, sin resultado favorable. Algunas pacientes habían padecido la enfermedad hasta etapas avanzadas de los embarazos anteriores. En todas se prescindió del uso de droga

En este grupo, el vómito estaba acompañado indistintamente de los otros signos y síntomas que completan el cuadro sindromático de la hiperemesis: pérdida de peso, inapetencia, repugnancia por ciertos alimentos, depresión o irritabilidad, lipotimias, constipación intestinal, insomnio, sialorrea, dolor epigástrico, etc.

Los dos casos de parto espontáneo correspondieron a pacientes preparadas desde el octavo mes.

Los dos casos de parto intervenido recibieron condicionamiento por hipnosis el día anterior a la fecha del parto.

La técnica que empleamos fué, en líneas generales, la siguiente: Para los casos de hiperemesis gravídica, después de un detenido estudio clínico y eliminados los disturbios orgánicos que pueden ocasionar el síndrome, se llega a la conclusión de que sus factores etiológicos son predominantemente sicógenos.

Llegados a este punto, el paso siguiente consiste en un análisis minucioso en el que debemos encontrar la o las causas determinantes del desequilibrio emocional que se ha traducido en el conjunto de los síntomas enumerados anteriormente.

Acto seguido, la actividad se dirige a buscar una buena actitud mental del sujeto para la aceptación de la hipnosis. Esta actitud mental se logra mediante la ilustración de la paciente acerca de lo que es la hipnosis clínica, de la seriedad del procedimiento, de su inocuidad y sus beneficios. 
Después de este preámbulo y contando con la aceptación del tratamiento, se pide a la enferma tener fé en los resultados del método, colaborar por medio de una buena relajación física $\mathrm{y}$ mental y esperar que las sugestiones verbales la conduzcan al estado de trance hipnótico.

Después de esta preparación, se practican algunas pruebas de susceptibilidad. Nosotros empleamos la prueba de la levitación del brazo o la caída hacia atrás, preferentemente.

Si éstas son positivas, colocamos la paciente en una posición cómoda y procedemos a inducir el sueño por el método de la fijación de la mirada. Luego se avanza en la hipnosis hasta lograr el plano deseado. En este momento, de acuerdo con cada caso en particular, damos las órdenes o sugestiones posthipnóticas adecuadas: cesación o disminución gradual de la náusea y el vómito; corrección de la inapetencia, del estreñimiento, la abulia, etc., etc. La sesión tendrá una duración mínima de 20 minutos.

En los casos de parto espontáneo preparados desde el octavo mes, seguimos la misma técnica descrita anteriormente en lo referente a la actitud mental, a las pruebas de susceptibilidad y a la profundización. Pero la inducción se hizo en forma colectiva, con el método de la levitación del miembro superior.

Las órdenes post-hipnóticas se dirigieron a acabar con el temor del parto; a entrar en trance al iniciarse cada contracción, la cual vendrá sin dolor y a obedecer las órdenes referentes al pujo, el cual eliminará el dolor.

Durante el tiempo de preparación se les enseña la técnica de las respiraciones y el pujo, así como su aplicación en los distintos períodos del parto. En este grupo fueron suficientes cuatro sesiones, una semanal.

En los casos de parto intervenido, cuya preparación se inició el día anterior, hicimos dos sesiones con la misma técnica y las mismas sugestiones enunciadas para el grupo inmediatamente anterior.

\section{RESULTADOS}

Todas las pacientes con hiperemesis gravídica se beneficiaron con el tratamiento. Cinco curaron con una sesión; siete, con 
dos sesiones; cinco, con tres sesiones, y una, con cuatro sesiones. De las dos restantes, ambas con cuatro sesiones, en una hubo notoria mejoría y en la otra, disminución de la intensidad de los síntomas pero hubo necesidad de complementar el tratamiento con drogas.

De los dos casos de parto preparados desde el octavo mes, en uno hubo sensaciones dolorosas bastante tolerables y en el otro, según testimonio de la paciente, ausencia total de dolor.

En los dos casos intervenidos con fórceps y episiotomía, preparados desde el día anterior al parto, sus testimonios indican ausencia de dolor durante todo el trabajo e ignorancia del uso del fórceps y de la práctica de la episiotomía y su reconstrucción. En estos dos últimos casos no se empleó ninguna droga.

\section{CONCLUSIONES}

Recomendamos el empleo de la hipnoterapia en la hiperemesis gravídica, como una de las medidas más efectivas para su control.

Durante el parto, la hipnoterapia presta una valiosa ayuda en cuanto al dolor se refiere, aún en casos que requieren intervenciones por vía baja.

Aconsejamos insistir en la preparación en equipo de las embarazadas por el método hipnosugestivo para el parto sin dolor y el empleo más frecuente de este sistema.

\section{BIBLIOGRAFIA}

1 BRAID, J. Neuro hipnología. 1: Edición. Pág. 66 y siguientes, Editorial Poblet, Buenos Aires, 1960.

2 PARKYN, H. Terapéutica sugestiva e hipnotismo. 1ª Edición, Págs. 32, 51, 59, 83. Editorial Betal. Buenos Aires, 1961.

3 PAVLOV, I. P. El sueño y la hipnosis. 1: Edición. Pág. 159 y siguientes, Editorial Martínez de Murquia, Buenos Aires-Madrid, 1959.

4 DUPRAT, E. F. Hipnotismo. 4⿳亠丷 Edición. Págs. 17, 20, 49. Editorial Crespillo, Buenos Aires, 1959.

5 GINDES. B. C. Nuevos conceptos sobre el hipnotismo. 1: Edición, Págs. 180 y siguientes, Editorial Psique, Buenos Aires, 1959. 